\title{
Flaming Ignition Behavior of Hot Steel and Aluminum Spheres Landing in Cellulose Fuel Beds
}

\author{
CASEY ZAK, JAMES URBAN, VI TRAN, CARLOS FERNANDEZ-PELLO \\ Department of Mechanical Engineering \\ University of California Berkeley, Berkeley, USA
}

\begin{abstract}
The ignition of combustible material by hot metal particles is an important fire ignition pathway that remains relatively unstudied. In this work, the flaming ignition behavior of powdered cellulose fuel beds by hot steel and aluminum spheres of various diameters and initial temperatures was studied. Understanding ignition in this scenario could offer insight into the mechanisms by which metal particles initiate wildland fires and fires in industrial settings. Earlier work on this topic has shown that ignition propensity has a relationship with the temperature and diameter of the sphere. However, little is known about the physical processes governing this relationship. This work provides further information regarding the conditions required for ignition, and useful observations for the development of a theoretical framework for predicting ignition propensity of combustible fuel beds. For the conditions tested, powdered cellulose ignition appears to exhibit limiting behavior in two regimes: for larger spheres, temperatures below $600^{\circ} \mathrm{C}$ did not ignite the cellulose and spheres with diameters below $2.38 \mathrm{~mm}$ for steel or $2.03 \mathrm{~mm}$ for aluminum and temperatures up to $1100^{\circ} \mathrm{C}$ did not ignite the cellulose either. We also observed that in the range of sphere diameters from 4-8 $\mathrm{mm}$, aluminum spheres of a given diameter are more likely to cause ignition than their steel counterparts. This seems to be due to the fact that the aluminum spheres are molten at temperatures greater than $657.2{ }^{\circ} \mathrm{C}$; melting contributes to a spheres bulk energy through the latent heat of melting and allows for sphere deformation and splatter during impact. Furthermore, qualitative analysis of high speed schlieren videos shows differences in pyrolysis and ignition behavior and suggests that, different controlling processes may be at work for spheres of different sizes and for molten versus solid spheres.
\end{abstract}

KEYWORDS: ignition, hot particles, wildfires, cellulose, fuel beds, statistics, high-speed imaging, hot working

\section{INTRODUCTION}

The ignition of natural combustible material by hot metal particles is an important fire ignition pathway for wildland urban interface (WUI) fires and fires in industrial settings. These particles can be the result of powerline interactions, friction within machinery, welding or other industrial activities. Small particles generated by these sources can be carried large distances by wind. Thus, even combustible material some distance away from a particle source is at risk of ignition. Potential fuel beds include forest litter, dry grass, sawdust and cellulosic building materials [1].

There are many examples of wildland fires started by hot metal particles; unfortunately, many of these events end up in litigation and their case studies are not published. One notable example of vegetation ignited by hot metal particles is the Witch and Guejito fires in southern California [2]. Particles generated by power line interaction in high winds started two fires and caused large amounts of land and property damage in 2008. Another recent large wildland/urban fire is the Bastrop County Complex wildfire, which was the largest-loss fire in the United States in 2011 and burned 12,787 hectares [3]. The fire allegedly started when power lines contacted during high winds and sparks ignited dried grass and vegetation. Outside of the United States, 275 fires in New Zealand were ignited by embers, sparks or flying brands between 2005 and 2010 [4]. Particles produced by welding, grinding and various forms of hot work have also been involved in several notable incidents, and the established literature discusses many potential particle sources [1,5].

Despite these examples, the topic remains relatively unstudied. Work has been conducted on the relationship between size, temperature and trajectory for these particles, but the conditions necessary to initiate a spot fire are not well understood [6]. Consequently, current wildland fire models lack capabilities for accurately predicting the initiation of spot fires and industrial safety regulators lack information on this topic[1,7,8]. A greater understanding of the conditions necessary for ignition could lead to improved predictive models and FIRE SAFETY SCIENCE-PROCEEDINGS OF THE ELEVENTH INTERNATIONAL SYMPOSIUM pp. 1368-1378 
reduced losses due to fire. There are a limited number of studies published on the ignition of fuel beds by hot metal particles [9-14]. The work presented here focuses on the ignition of powdered cellulose fuel beds by hot metallic spheres. The goal of this approach is to use a simplified laboratory case to understand the controlling parameters and underlying mechanisms at work in real world ignition scenarios. We performed ignition experiments for both steel and aluminum spheres, over a range of sphere diameters and temperatures. This allowed us to investigate ignition likelihood dependence on sphere diameter, temperature and thermal properties. In addition, we recorded high-speed radial Schlieren video of the ignition events and observed both sphere and gas-phase dynamics shortly before ignition. In the following sections, we briefly describe our experimental method and then discuss the observed ignition behavior and how it depends on the parameters under study.

\section{EXPERIMENTAL DESCRIPTION}

In this investigation, stainless steel (alloy 302) and aluminum (alloy 1100) spheres were heated using a tube furnace and dropped onto a fuel bed seated inside the test section of a bench-scale wind tunnel. The diameter and temperature of the stainless steel spheres were varied between $2.38 \mathrm{~mm}$ and $15.88 \mathrm{~mm}$ and $575^{\circ} \mathrm{C}$ to $1000^{\circ} \mathrm{C}$ respectively. For aluminum, we tested diameters from $3.18 \mathrm{~mm}$ to $7.92 \mathrm{~mm}$ and temperatures from $600^{\circ} \mathrm{C}$ to $950^{\circ} \mathrm{C}$. The diameter range for aluminum was limited by commercial availability. For stainless steel, the largest sphere diameter was limited by the furnace orifice dimensions. The lower diameter limit was determined experimentally as the smallest diameter where ignition still occurred at the maximum temperature of the furnace $\left(1000^{\circ} \mathrm{C}\right)$. We investigated the larger diameters to assess the potential differences in ignition mechanism between large and small spheres. These diameter ranges are most representative of overheated machine parts and welding splatter [1]. Additionally, the phenomenological description developed from the Schlieren video footage can be extended to smaller, hotter particles.

The motivation for using aluminum alloy 1100 is its use in electrical power lines. Stainless steel was chosen for its availability and as a reasonable representative of particles created by welding or machine friction. Fuel beds were composed of powdered $\alpha$-cellulose $\left(\left(\mathrm{C}_{6} \mathrm{H}_{10} \mathrm{O}_{5}\right)_{n}\right)$. Cellulose was chosen for its chemical homogeneity and the availability of property data. Furthermore, cellulose is the largest component of woody biomass, making it a reasonable surrogate for more complex fuels (such as sawdust or duff). According to data provided by the manufacturer (Sigma-Aldrich), the cellulose particle size distribution was approximately normal, with a mean of $0.19 \mathrm{~mm}$ and standard deviation of $0.36 \mathrm{~mm}$. Cellulose settled volume was held constant for all experiments. Here, the settled volume refers the minimum volume occupied by the fuel bed after vigorous vibration. Fuel bed bulk density varied normally about a mean of $338 \pm 40 \mathrm{~kg} / \mathrm{m}^{3}$, slightly higher than the range stated by the manufacturer. The fuel beds were laboratory-conditioned and we measured the moisture content of the fuel for each daily series of experiments. This involved drying labconditioned samples in an oven at $110 \pm 5^{\circ} \mathrm{C}$ for at least 4 hours. Each sample weighed at least $1.3 \mathrm{~g}$ and the mass was measured before and after drying.

\section{Experimental Apparatus}

The experimental apparatus is shown in figure 1 . The fuel bed is seated flush with the bottom of the wind tunnel. Laboratory air is flown through the wind tunnel section with a centerline velocity of $0.5 \mathrm{~m} / \mathrm{s}$ at the leading edge of the fuel bed. While wind speed is a potentially important parameter for this problem, in this work we chose to hold the cross-flow velocity constant. This particular velocity was chosen because it is on the order of buoyancy-induced flow speeds, and it produces a more regular flow without overly disturbing the fuel surface. Flow uniformity is reduced when the tunnel top is opened to introduce the spheres. To overcome this complexity and ensure a uniform cross-flow velocity between tests, tests were only conducted on the leading half of the fuel bed. The relative humidity and temperature of the flow were measured daily and found to be $13.1 \% \pm 1.8 \%$ and $26.3 \pm 0.45^{\circ} \mathrm{C}$ respectively. Viewing windows in the sides of the tunnel allow optical access for Schlieren video recording (see figure 2). The Schlieren system utilizes a double pass configuration with a color bullseye (blue center, yellow and red rings) and a spherical mirror with a focal length of $1 \mathrm{~m}$. Videos were recorded at 1200 frames per second (fps) using a digital camera.

A linear guide holds a ceramic spoon approximately $140 \mathrm{~mm}$ above the fuel bed. This guide is collinear and concentric with a high-temperature tube furnace such that the spoon can easily be inserted and removed from 
the furnace. A type $\mathrm{K}$ thermocouple is embedded in the spoon to provide an accurate estimate of the sphere temperature. The spoon is coated with boron nitride, a wetting deterrent. The maximum effective temperature of boron nitride is around $980^{\circ} \mathrm{C}$, limiting the temperature at which aluminum experiments can be performed.



Fig. 1. Experimental setup in an isometric view with cutout.

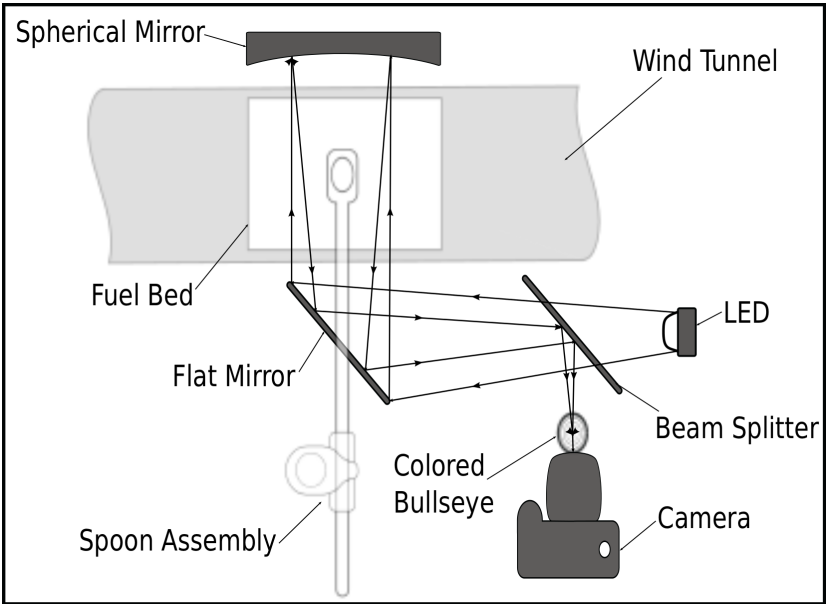

Fig. 2. Bird's eye view of experimental setup with optical components.

\section{Experimental Procedure}

During each run, we placed a sphere in the ceramic spoon and inserted the spoon into the tube furnace. The sphere remained in the furnace until the spoon thermocouple indicated that the spoon and sphere were at a steady state at the desired temperature. The spoon was then rapidly removed from the furnace and rotated, dropping the sphere onto a virgin area of the fuel bed. For each set of test conditions, drop locations were varied and tests were performed on multiple beds to randomize contributing factors associated with the fuel bed.

For the purposes of labeling each recorded event, we defined 'flaming ignition' as the appearance of a stable flame that persisted for more than 1 second after the sphere contacted the bed. The study of smoldering ignition is an important and related topic, but it introduces additional complexity associated with self-supported smoldering fronts and the transition from smoldering to flaming. As a result, the scope of this work is restricted to flaming ignition and incipient smoldering ignition was recorded as a non-ignition event. Experiments focused on testing conditions near the flaming/non-flaming limit. Previous work by our lab has shown FIRE SAFETY SCIENCE-PROCEEDINGS OF THE ELEVENTH INTERNATIONAL SYMPOSIUM pp. 1368-1378 
that relative to the parameters of interest, ignition behavior is stochastic in nature $[12,13]$. Thus, at least five experiments were performed for each combination of diameter and temperature that we investigated.

\section{RESULTS}

\section{Ignition Probabilities}

The ignition results are shown below in figure 3 for steel spheres and figure 4 for aluminum spheres. Each circle denotes a combination of sphere diameter and temperature. The shade of the circle indicates $\hat{p}$, the maximum likelihood estimate (MLE) of the probability of ignition, calculated as

$$
\hat{p}=\frac{\text { number of tests resulting in flaming ignition }}{\text { number of total tests }} .
$$

We expect the ignition to behave binomially for each parameter combination since each test resulted in either ignition or no ignition. With a sample size of 5, the binomial distribution is non-normal, and parameter estimates have some degree of uncertainty (see 1).

Table 1. Clopper-Pearson confidence intervals for ignition probability at a $90 \%$ level of confidence for 5 tests

\begin{tabular}{|l|c|c|}
\hline$y_{i}$, number of ignitions & $\hat{p}_{l}$, lower confidence bound & $\hat{p}_{u}$, upper confidence bound \\
\hline 0 & 0 & 0.451 \\
1 & 0.010 & 0.657 \\
2 & 0.076 & 0.811 \\
3 & 0.189 & 0.924 \\
4 & 0.343 & 0.990 \\
5 & 0.549 & 1.000 \\
\hline
\end{tabular}

Despite this uncertainty, the data demonstrates clear trends and meaningful observations can still be made. The data set shown can be thought of as approximating a transition region between cases of non-ignition (black circles) and ignition (white spheres). In an attempt to better represent the trend of the data, we also performed a logistic regression of the form

$P=\frac{1}{1+e^{\left(A d_{s}+B d_{s} T_{s}+C T_{s}+D\right)}}$.

where $P$ is the probability of ignition and $d_{s}$ and $T_{s}$ are the diameter (in $\mathrm{mm}$ ) and temperature (in degrees Celsius) of the sphere, respectively. The values of the fitting constants $A, B, C$ and $D$ for steel and aluminum are summarized in table 2 . The black trend lines in figures 3 and 4 represent a $50 \%$ ignition probability according to this regression. All diameter/temperature pairs located to the right of the line have greater odds of igniting than not igniting; the opposite is true for those pairs to the left of the line.

Table 2. Fitting constants for ignition probability relation

\begin{tabular}{|l|c|c|}
\hline Sphere Material & Stainless Steel 302 & Aluminum 1100 \\
\hline$A$ & -391.58 & -306.02 \\
$B$ & 0.66 & 0.47 \\
$C$ & -1.56 & -1.44 \\
$D$ & 669.35 & 908.53 \\
\hline
\end{tabular}




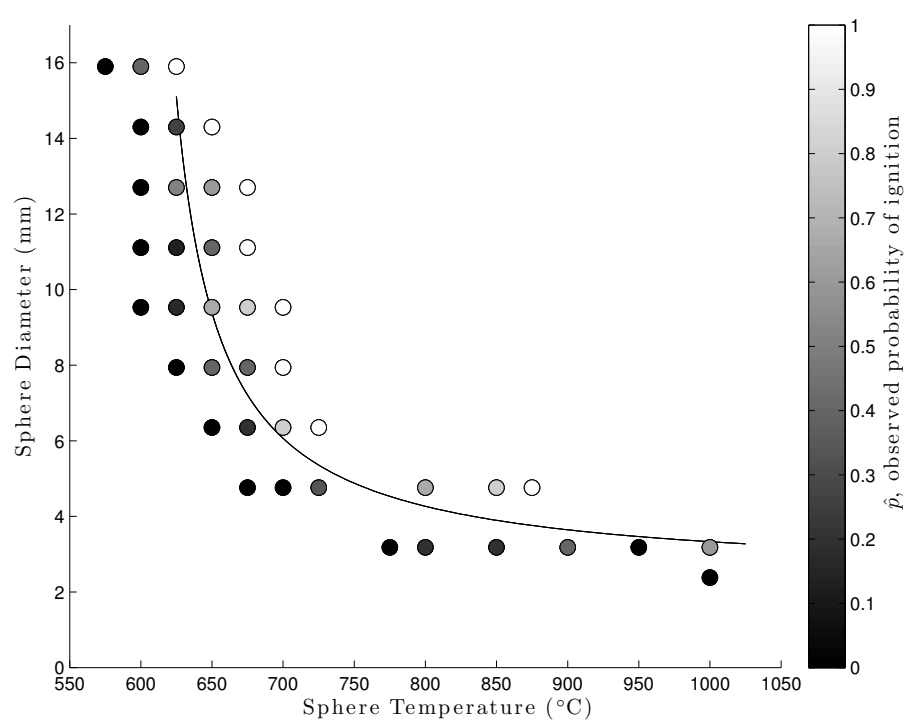

Fig. 3. Ignition probability for stainless steel spheres.

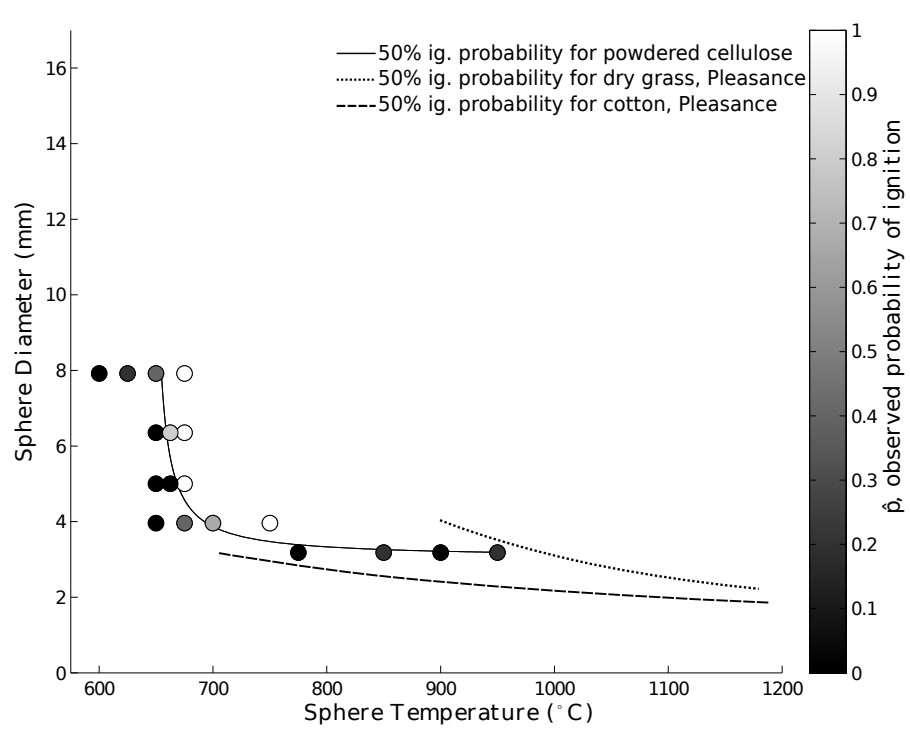

Fig. 4. Ignition probability for aluminum spheres, with the limits of two other fuels for comparison.

Qualitatively, the results for both metals show that spheres of decreasing size require higher temperatures to ignite, which indicates that sphere bulk energy plays a role in the cellulose ignition process. The ignition likelihood of very small spheres also appears to be relatively insensitive to temperature. Figure 3 shows that ignition by large stainless steel spheres additionally becomes less sensitive to diameter as sphere size increases. A similar effect is observed with aluminum, but in this case the effects of melting must also be taken into account (see below).

These characteristics suggest somewhat asymptotic behavior for very large and very small spheres, at least for the ranges of diameters and temperatures tested. This has also been observed in previous studies [12-14]. For steel spheres, the apparent low temperature asymptote seems to lie somewhere between 500 and $600^{\circ} \mathrm{C}$ and the small diameter asymptote appears to lie somewhere between 2 and $3 \mathrm{~mm}$. Further testing is required 
to confirm this behavior holds true for a wider range of sphere diameters and temperatures. It should be noted that spheres of either metal with $d_{s}<=3.18 \mathrm{~mm}$ never achieved greater than $20 \%$ observed ignition probability at any of the temperatures investigated.

For comparison, figure 4 shows the approximate 50\% flaming ignition probability curves for dry grass and cotton wool when ignited by aluminum spheres (of a very similar aluminum alloy to 1100) [10]. These curves were estimated from dot-style plots in an unpublished report written by Pleasance and referred to by Rowntree and Stokes in their own study of hot particle ignition [11]. The three curves are qualitatively and quantitatively similar, reinforcing the assumption that cellulose is an adequate surrogate for some natural fuels. Given that cotton fiber is almost pure cellulose, we would expect that there would be good agreement between the ignition behavior of powdered cellulose and cotton wool. The fact that cotton wool seems to ignite at smaller diameters than powdered cellulose for a given temperature may be due to the large density difference between the fuels and the proximity of oxidizer afforded by the cotton wool's structure. Natural fuels like dry grass contain hemicellulose and lignin in addition to cellulose, and as a result we expect them to be more difficult to ignite. In agreement with this expectation, figure 4 shows that dry grass requires a larger diameter to ignite at a given temperature than powdered cellulose or cotton wool. However, even though the dry grass and cotton wool curves appear to have decreased sensitivity to temperature at small diameters, the effect is not as marked as with the current aluminum tests. The discrepancy in behavior may be due to the limited testing range and low number of tests at each diameter/temperature pair conducted for this study.

The comparison between the ignition behavior of steel and aluminum spheres is shown in figure 5 .

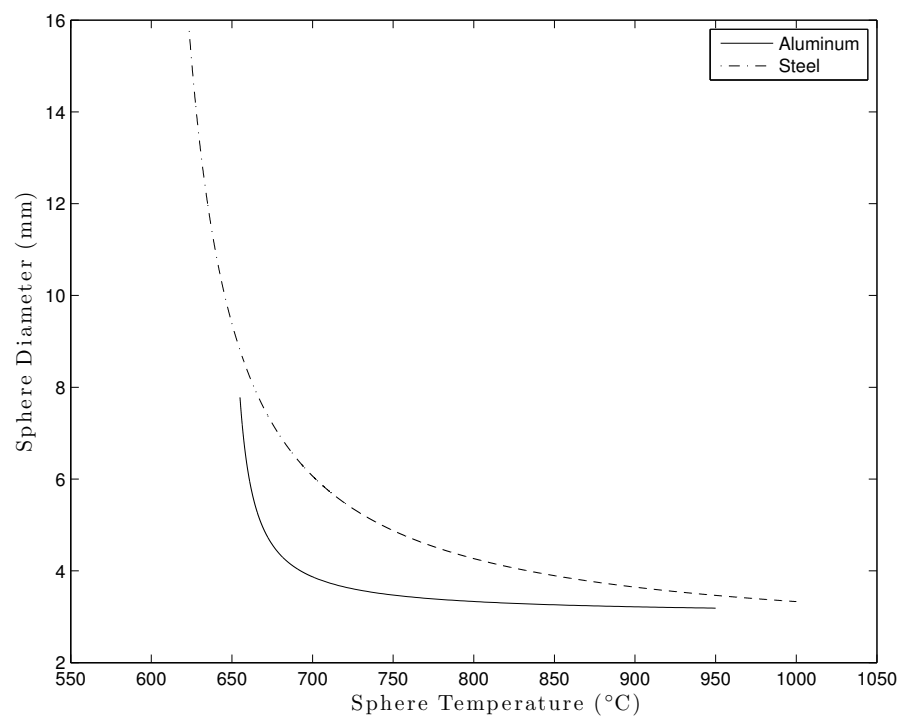

Fig. 5. Comparison of 50\% ignition likelihood trendlines.

For a given sphere diameter, aluminum spheres cause ignition at lower temperatures than steel spheres for $d_{s} \sim 4-8 \mathrm{~mm}$. This is most likely due to the fact that aluminum alloy 1100 is molten over most of the temperature range tested, while steel alloy 302 remains solid throughout (see table 3)[15-17]. The aluminum trend line also exhibits a much sharper curvature in $d_{s}-T_{s}$ space, right around the liquidus temperature of the aluminum. Previous work in our laboratory has suggested that the asymptotic behavior described earlier is indicative of two regimes: a large diameter regime where cellulose ignition is only dependent on sphere surface temperature, and a small diameter regime where both bulk energy and temperature play important roles [14]. This is highlighted by figure 6 , which shows sphere energy along the $50 \%$ ignition probability line as a function of diameter for both materials. 
Table 3. Thermal properties of stainless steel and aluminum.

\begin{tabular}{|l|c|c|r|}
\hline Sphere Material & Stainless Steel 302 & Aluminum 1100 & Molten Aluminum 1100 \\
\hline$T_{s}$, solidus temperature $\left({ }^{\circ} \mathbf{C}\right)$ & 1400 & 643 & 643 \\
$T_{l}$, liquidus temperature $\left({ }^{\circ} \mathbf{C}\right)$ & 1420 & 657.2 & 657.2 \\
$\Delta h_{f}$, heat of melting $(\mathbf{k J} / \mathbf{k g})$ & $\mathrm{N} / \mathrm{A}$ & 390 & 390 \\
$\rho c$, volumetric heat capacity $\left(\mathbf{M J} / \mathbf{m}^{3} \mathbf{K}\right)$ & 3.93 & 2.45 & 2.71 \\
$k$, thermal conductivity $(\mathbf{W} / \mathbf{m K})$ & 21.5 & 220 & 90.7 \\
\hline
\end{tabular}

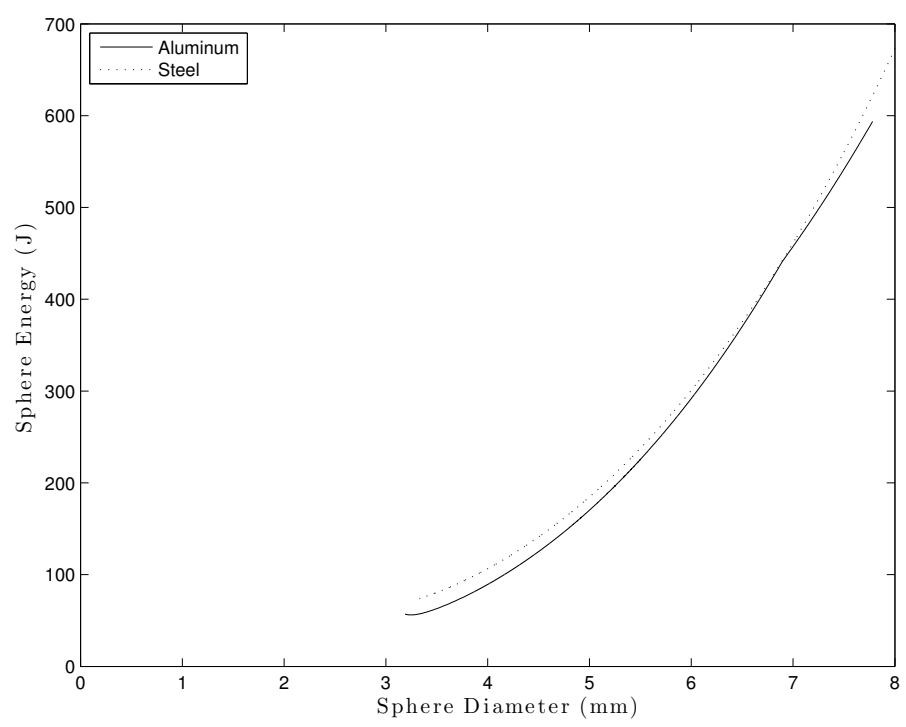

Fig. 6. Sphere energy along the $50 \%$ ignition curve as a function of diameter.

Clearly, the energy of spheres capable of causing ignition at a given diameter is very similar between the two materials. Interestingly, the two curves agree the best in the range of diameters for which the differences in ignition temperature are the most marked. It appears that being molten increases the energy of the aluminum spheres such that they meet some necessary requirement of ignition that steel spheres only meet at higher temperatures. However, the lack of agreement at small diameters and the fact that the ignition energy varies with diameter indicate that there is a necessary, but not sufficient criteria for ignition associated with bulk sphere energy.

It is important to note that changing a sphere's composition could affect its bulk energy regardless of melting, and that effect must be taken into account. However, in the case of aluminum and stainless steel, aluminum has a slightly lower volumetric heat capacity than steel and thus would need a higher, not lower, temperature to ignite (without the effect of melting). It should also be noted that aluminum has a thermal conductivity that is an order of magnitude larger than that of steel and this may explain the deviation at larger diameters present in figure 6 and why ignition occurred at lower temperatures even for the one diameter $\left(d_{s}=7.9 \mathrm{~mm}\right)$ that was solid for both aluminum and stainless steel. Melting also affects a sphere's impact dynamics, and this effect is discussed in the following section.

\section{Ignition Phenomenology}

Following completion of the experiments, high-speed video of each of the events was analyzed. As mentioned previously, test resulted in either flaming ignition or no ignition. A sequence of still frames from two steel ignition tests with the same $d_{S}$ and $T_{S}$ but different outcomes are shown with timestamps in figure 7 . The small 


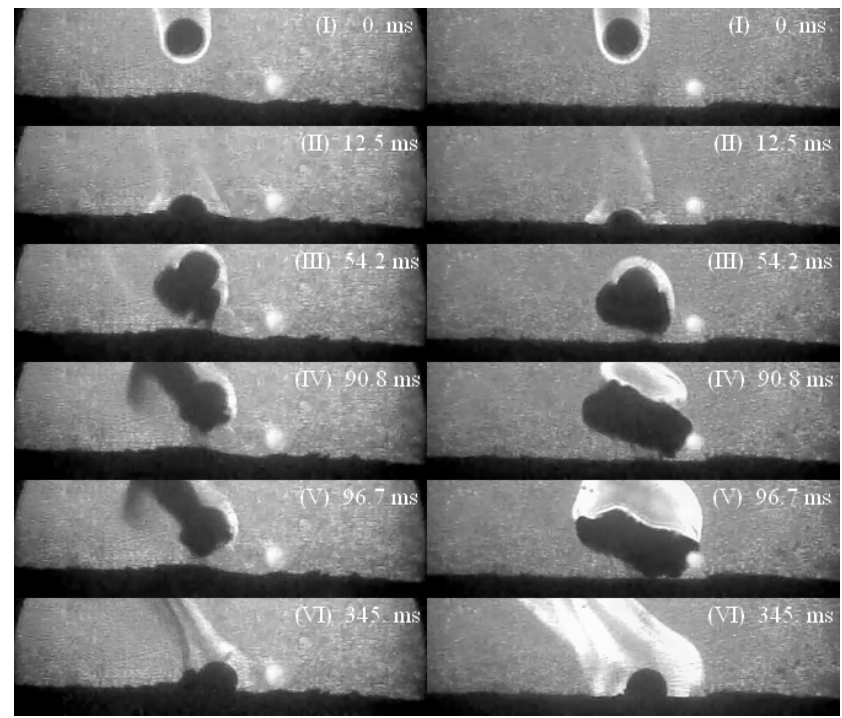

Fig. 7. Non-ignition (left) and ignition (right) events for stainless steel spheres with $d_{s}=7.94 \mathrm{~mm}$ and $T_{s}=675^{\circ} \mathrm{C}$.

bright circle that appears near the lower middle of all frames is an artifact of the Schlieren imaging technique and is not involved in the ignition process.

A general sequence of events is common to all recorded tests. First, the sphere, followed by its Schlieren contrail, is seen impacting the fuel bed (frames I-II, figure 7). Many spheres then bounce and may or may not spin (frames III, figure 7). Shortly after impact, a Schlieren contour expands away from the sphere, indicating the expansion or growth of a hot gas volume. Initially, this may be hot air being pushed out of the way by the impinging sphere, but a continued presence around the sphere, especially when airborne, indicates the production of gaseous pyrolyzate generated as the sphere heats the cellulose on its surface. In many cases (particularly those with larger spheres and lower temperatures), a dark plume is observed emanating from the sphere at some time after the initial impact (frames III-V, figure 7). A dark appearance in a Schlieren image means an object is opaque, suggesting either cellulose particles lofted by the sphere's impact or heavier products of pyrolysis. The current resolution of the videos $(0.22 \mathrm{~mm})$ means that the presence of small lofted cellulose cannot be resolved. However, it should be noted that in the cases of bouncing spheres (like the one shown in figure 7) the plumes appear to track the sphere, which seems nonphysical for particles lofted by impact. Assuming the cloud is at least partially fluid in nature, it seems likely that the opacity is due to a combination of solid and condensed pyrolysis products.

In the cases of non-ignition, a dark plume persists for a time and then dissipates, leaving only a Schlieren contour resulting from heating of the airflow by the sphere (frame VI, left hand side of figure 7). When ignition does occur, it is clearly observed as a rapid expansion of the existing hot gas contour, or as a second contour that nucleates within the first (frame IV, right hand side of figure 7). If a dark plume is present, it is consumed but the expanding front (frame V, right hand side of figure 7). After the flame front is initiated, it grows in size and eventually anchors to the fuel bed, becoming a diffusion flame (frame VI, right hand side of figure 7). When a second contour is observed, its location can vary greatly; ignition occurred on both the bottom and top surfaces of spheres during bouncing.

As discussed previously, we hypothesize that the apparent limiting behavior at low temperatures and small diameters is the result of two regimes with different controlling parameters. This hypotheses is partially motivated by the different ignition behavior observed for large spheres and small spheres of the same material, as shown in figure 8. Note that the smaller sphere does not form any dark plume, but instead forms a more prominent Schlieren contour (frames III-IV, right hand side of figure 8 . When ignition does occur, it happens 


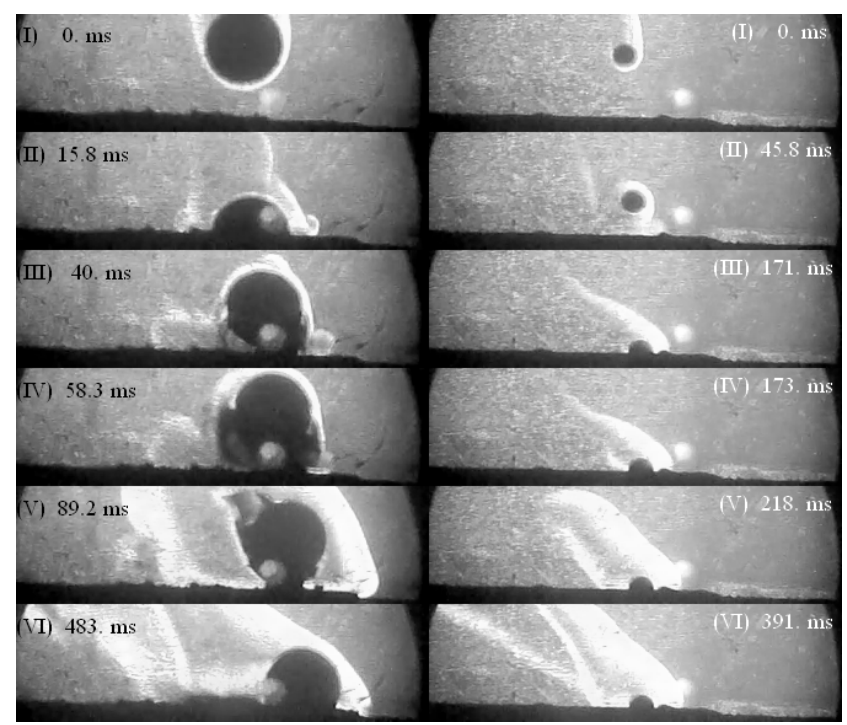

Fig. 8. Ignition events for $15 \mathrm{~mm}$ (left) and 4.76 (right) $\mathrm{mm}$ stainless steel spheres.

much later in time and involves a moderate, but still rapid, expansion of the currently existing hot gas contour (frames V-VI, right hand side of figure 8).

Melting also had a marked effect on the impact behavior of the aluminum spheres (see figure 9). The solid aluminum spheres appear to exhibit the same phenomenology as the steel spheres (left side of figure 9). On the other hand, the molten spheres impact much more violently, and loft large cellulose particles, as seen in the rightmost portions of frames II-V in figure 9. Even small spheres create a large dark plume, and when ignition occurs it appears to initiate at the edges of this plume, suggesting that in this case a lofted cellulose dust may be igniting. Interestingly, the time to ignition for the solid and molten spheres is very similar (frame $\mathrm{V}$, figure 9). It is unclear how much this different impact behavior would increase ignition propensity, given that the particle lofting, enhanced mixing and heat transfer that result from the flattening of the sphere may be balanced by increase in the surface area to volume ratio of the shape and the resulting increased losses due to radiation and convection. Further study is needed to assess the importance of impact characteristics for determining ignition likelihood.

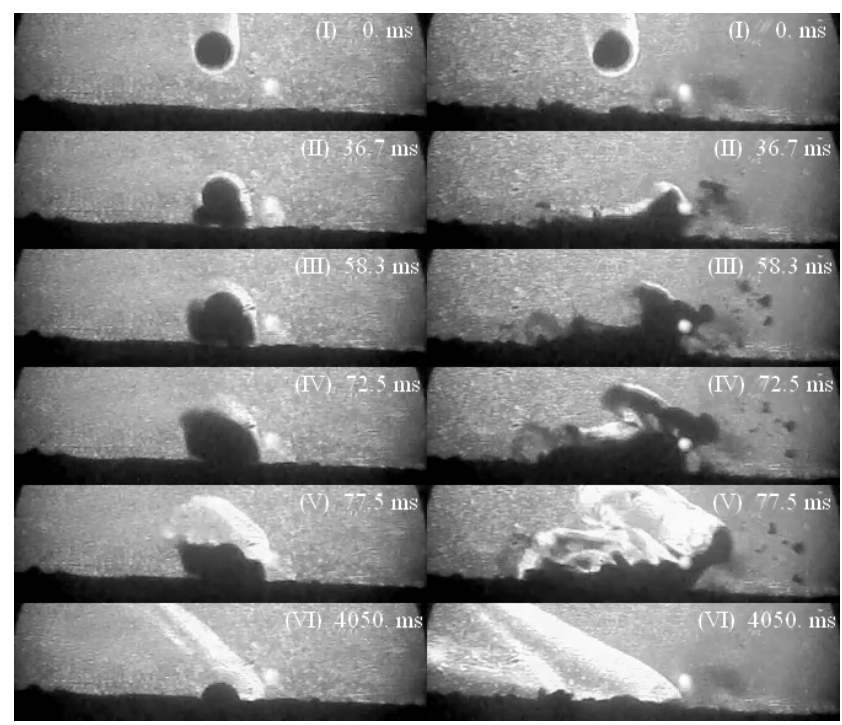

Fig. 9. Ignition events for $7.92 \mathrm{~mm}$ aluminum spheres: molten at $675^{\circ} \mathrm{C}$ (left) and solid at $625^{\circ} \mathrm{C}$ (right). 


\section{CONCLUSION}

Ignition tests have been performed over a range of sphere temperatures and diameters for both aluminum and stainless steel spheres, and high-speed schlieren video was used to observe and describe the ignition process. Aluminum spheres were found to have greater ignition propensity than stainless steel spheres for diameters between $\sim 4$ and $8 \mathrm{~mm}$; this is most likely the result of their increased bulk energy due to the heat of fusion and potentially also the different impact dynamics of molten objects. At large diameters, ignition behavior for stainless steel spheres appears to be less sensitive to diameter, while both steel and aluminum spheres exhibit limiting behavior around diameters of 2-3 $\mathrm{mm}$ for the temperatures tested. Agreement with previous studies also indicates that cellulose may be a reasonable surrogate for more complex natural fuel beds. Further work is required to expand the diameter and temperatures ranges under study and to quantify the effect of changing thermal properties in the absence of melting.

\section{ACKNOWLEDGEMENTS}

The authors would like to thank Daniel Wagman and Daniel Murphy for their contributions to this work. This research was supported by National Science Foundation Award No. CBET-1066520 and a National Science Foundation Graduate Research Fellowship. 


\section{REFERENCES}

[1] Babrauskas, V. Ignition Handbook: principles and applications to fire safety engineering, fire investigation, risk management and forensic science, Fire Science Publishers, Issaquah, Washington 98027, 2003.

[2] Maranghides, A. and Mell, W. NIST Technical Note 1635: A Case Study of a Community Affected by the Witch and Guejito Fires. National Institute of Standards and Technology, Gaithersburg, Maryland 20899, 2009.

[3] Badger, S.G. Large-Loss Fires in the United States - 2011. National Fire Protection Association, Quincy, Massachusetts 02169, 2012.

[4] Emergency Incident Statistics 2009-2010. New Zealand Fire Service, Wellington, New Zealand, 2010.

[5] NFPA 51B, Standard for Fire Prevention During Welding, Cutting and Other Hot Work, 2014 ed., App. B. National Fire Protection Association, Quincy, Massachusetts 02169, 2014.

[6] Tse, S.D. and Fernandez-Pello, A.C.. On the Flight Paths of Metal Particles and Embers Generated by Power Lines in High Winds a Potential Source of Wildland Fires. Fire Safety Journal, 1998, p. 333-356, http://dx.doi.org/10.1016/S0379-7112(97)00050-7.

[7] Linn, R., Resiner, J., Colman, J.J. and Winterkamp, J. Studying wildfire behavior using FIRETEC. International Journal of Wildland Fire, 2002, p. 233-246, http://dx.doi.org/10.1071/WF02007.

[8] Finney, M.A. FARSITE: Fire Area Simulator-model Development and Evaluation, Research Paper RMRS -RP4. U.S. Department of Agriculture, Forest Service, Rocky Mountain Research Station, 1998.

[9] Tanaka, T. On the Flammability of Combustible Materials by Welding Splatter. Reports of the National Research Institution of Police Science, 1977, p. 151-158.

[10] Pleasance, G.E. Ignition of grass by hot aluminum particles. An Examination of Particles from Conductor Clashes as Possible Sources of Bushfire Ignition, Appendix 5. State Electricity Commission of Victoria, Victoria, Australia, 1977, unpublished.

[11] Rowntree, G.W. and Stokes, A.D. Fire ignition by aluminum particles of controlled size. Journal of Electrical and Electronics Engineering, Australia, 1994, p. 117-123.

[12] Hadden, R.M., Scott, S., Lautenberger, C. and Fernandez-Pello, A.C. Ignition of Combustible Fuel Beds by Hot Particles: An Experimental and Theoretical Study. Fire Technology, 2011, p. 341-355, http://dx.doi.org/10.1007/s10694-010-0181-x.

[13] Zak, C., Tjahjono, E., Rich, D. and Fernandez-Pello, C. Ignition of Powdered Fuels by Hot Particles: An Experimental Study. In Forest Fires 2012, New Forest, UK, 2012.

[14] Zak, C., Urban, J. and Fernandez-Pello, C. Ignition Behavior of Hot Spheres Landing in Combustible Fuel Beds (Paper \#232). In International Colloquium on the Dynamics of Explosions and Reactive Systems, Taipei, 2013.

[15] Metals Handbook, Boyer, H.E. and Gall, T.L. (ed.), American Society for Metals, Materials Park, Ohio, 1985.

[16] Ho, C.Y., Powell, R.W. and Liley, P.E. Thermal Conductivity of the Elements. Journal of Physical and Chemical Reference Data, 1972, p. 279 - 421, http://dx.doi.org/10.1063/1.3253100.

[17] Chase, M.W. NIST-JANAF Thermochemical Tables, 4th ed. American Institute of Physics, 1998. 